\title{
Modelling and validation of a multi-phase traffic light controlled cross-type intersection using timed coloured petri nets
}

\author{
*Ganiyu R. A., Olabiyisi S. O., Omidiora E. O., Okediran O. O. and Alo O. O. \\ Department of Computer Science and Engineering, \\ Ladoke Akintola University of Technology, P.M.B 4000, Ogbomoso, Nigeria. \\ ${ }^{*}$ Corresponding author
}

\begin{abstract}
This paper focuses on the use of Timed Coloured Petri Nets (TCPN) to model a multi-phase traffic light controlled cross-type intersection using cross-type junction of fixed signal timing plan located in Federal Capital Territory, Abuja, Nigeria, as a case study. The validation of developed TCPN model is explored by carrying out a statistical analysis between the simulated and the measured number of vehicles crossing the intersection through each stream for fifteen cycles. Out of the total simulated number of vehicles crossing the Cross-type intersection through its four input links, Festival Road From South experienced the highest traffic congestion with $35.1 \%$ traffic volume, followed by Muhammed Buhari Way From East with $34.3 \%$ traffic volume, followed by Festival Road From North with $21.6 \%$ traffic volume while Muhammed Buhari Way From West experienced the least traffic congestion with $9 \%$ traffic volume. Statistically, during the fifteen cycles, there were no significant differences between the simulated and the measured numbers of vehicles crossing the Cross-type intersection at $5 \%$ level. Arising from the validation of the developed TCPN model, the simulation results give a confirmation of the developed TCPN model's efficacy to correctly describe the traffic behavior in the considered Cross-type intersection.
\end{abstract}

Keywords: Timed Coloured Petri Net, Cross-type intersection, Traffic light, Sub-model, Strategy.

\section{INTRODUCTION}

The phenomenon of traffic congestion has become predominant in urban road networks owing to the rapid increase in the number of vehicles and transportation demands. Despite the large research efforts on traffic management, the problem of urban intersection congestion remains an open issue (Papageorgiou, 1999). However, in urban road networks, the traffic lights at intersections regulate and guide transportation for the purpose of improving the safety and efficiency of vehicles; it manages conflicting requirements for the use of road space often at road junctions - by allocating right of way to different sets of mutually compatible traffic movements during distinct time intervals. Most of the currently implemented traffic control systems may be grouped into two principal classes (Patel and Ranganathan, 2001; Papageorgiou et al., 2003): (i) Fixed-time strategies and (ii) Traffic-response strategies. In most of industrialized countries, an urban traffic control of fixed-time strategies has been in practice till nowadays (Huang and Chung, 2008).
In a fixed-time strategy, the light control phases (i.e. the duration of green and red light) are scheduled offline. The light control phases are derived from historical data measured in a given intersection. There are typically several light control phases for each intersection, depending on the given time of the day. It is equally important to notice that the fixedtime strategy cannot respond to any change in traffic condition since their settings are based on historical data rather than real-time data. On the other hand, traffic-response strategy is based on feedback from the current state of traffic. It receives real-time data through sensors and creates an optimal timing plan. In a real-time control strategy, detectors located on the intersection approaches monitor traffic conditions and feed information on the actual system state to the real-time controller. Moreover, the controller selects the duration of the green phases in the signaltiming plan in order to optimize a performance index (|Patel and Ranganathan, 2001; Wey, 2000; Dotoli et al., 2003). In both control strategies, the traffic network has to be appropriately modelled, either for simulation purposes or in order to determine on line some states of the transportation network that are not 
available due to detector absence or failures (Gabard, 1991).

Meanwhile, Petri nets have been proven to be a powerful modeling tool for various kinds of discrete event systems (Murata, 1989; Peterson, 1981), and its formalism provides a clear means for presenting simulation and control logic. Hence, the Petri nets are applied in traffic control. Unlike high level Petri nets (i.e. Coloured Petri Nets), in addressing traffic congestion problems, a variety of low-level Petri nets reported in literature are not flexible enough to model multi-phase signalized intersections because of their inherent non-modular formalisms and state explosion problems. Coloured Petri net (CPN) is a graphical oriented language for modelling and validation of systems in which concurrency, communication, and synchronization play a major role. It is a discreteevent modeling language combining the classical Petri nets with the functional programming language Standard ML. More specifically, Petri nets provide the primitives for describing synchronization of concurrent processes, while programming languages provide the primitives for definition of data types and manipulation of their data values (Jensen et al., 2007). A Coloured Petri Net model of a system is an executable model representing the states of the system as well as the events that can cause the system to change state. The inclusion of time concepts into the Coloured Petri Net model results in a model called Timed Coloured Petri Net (TCPN) model (Ganiyu et al., 2011a). In a Timed Coloured Petri Net model, a global clock models the passage of time and through this, it would be possible to calculate performance measures, such as the speed by which a system operates and throughput. Conclusively, owing to ever increasing traffic volumes in urban roads, this research work developed and validated Timed Coloured Petri Net (TCPN) model that could help in studying and improving traffic flow for a platoon of vehicles in the considered multiphase traffic light controlled cross-type intersection.

\section{RESEARCH METHODOLOGY}

Basic Definitions of Coloured Petri Net and Timed Coloured Petri Net: In developing the proposed model, the following basic definitions of Coloured Petri Net (CPN) and Timed Coloured Petri Net (TCPN) were employed:

In a formal way, a Coloured Petri Net is a tuple CPN $=(\Sigma, \mathrm{P}, \mathrm{T}, \mathrm{A}, \mathrm{N}, \mathrm{C}, \mathrm{G}, \mathrm{E}, \mathrm{I})$ where:

(i) $\quad \Sigma$ is a finite set of non-empty types, also called colour sets. (ii) $\quad \mathrm{P}$ is a finite set of places.

(iii) $\quad T$ is a finite set of transitions.

(iv) $\quad \mathrm{A}$ is a finite set of $\operatorname{arcs}$ such that: $\mathrm{P} \cap \mathrm{T}=\mathrm{P}$ $\cap A=T \cap A=\varnothing$.

(v) $\quad \mathrm{N}$ is a node function. It is defined from $\mathrm{A}$ into PXT $\cup$ TXP.

(vi) $\quad \mathrm{C}$ is a colour function. It is defined from $\mathrm{P}$ into $\sum$.

(vii) $\quad \mathrm{G}$ is a guard function. It is defined from $\mathrm{T}$ into expressions such that:

$\forall t \in T:[\operatorname{Type}(\mathrm{G}(\mathrm{t})) \quad=\mathrm{B} \quad$ Type $(\operatorname{Var}(\mathrm{G}(\mathrm{t})))$

$\subseteq \Sigma]$

(viii) $\quad E$ is an arc expression function. It is defined from $A$ into expressions such that:

$\forall a \in A: \quad\left[\operatorname{Type}(\mathrm{E}(\mathrm{a})) \quad=\quad \mathrm{C}(\mathrm{p})_{\mathrm{MS}}\right.$

Type $(\operatorname{Var}(E(a))) \subseteq \Sigma$ ] where $p$ is the place of $N(a)$.

(ix) I is an initialization function. It is defined from $P$ into closed expressions such that:

$\forall p \in P: \quad\left[\right.$ Type $\left.(\mathrm{I}(\mathrm{p}))=\mathrm{C}(\mathrm{p})_{\mathrm{MS}}\right]$ (Jensen, 1994).

A timed non-hierarchical Coloured Petri Net is a tuple TCPN $=\left(C P N, R, r_{0}\right)$ such that:

(i) $\quad \mathrm{CPN}$ satisfying the above definition.

(ii) $\mathrm{R}$ is a set of time values, also called time stamps. It is closed under + and including 0 .

(iii) $r_{0}$ is an element of $R$ called the start time (Huang and Chung, 2008).

Traffic Lights at Junctions: Traffic light signals are designed to keep traffic flowing smoothly and safely. The traffic light signals are meant to be obeyed at junctions by road users. However, the traffic lights of a generic traffic network are defined according to a signal timing plan, including green, red and yellow (amber) signals that in Nigerian cities (where available) correspond respectively to you may go on if the way is clear, stop and stop at the stop line (Ganiyu et al., 2011).

The Case Study: Figure 1.1 depicts the snapshot of a multi-phase traffic light controlled Cross-type intersection under consideration. The intersection is located in Federal Capital Territory, Abuja, Nigeria. Traffic is currently ruled in the intersection by a fixed time control strategy with an associated signal-timing plan. Besides, the intersection is regularly crossed by cars, trucks, public transportation buses and mopeds. Figure 1.2 also shows the layout of the Cross-type intersection. The layout consists of two roads named Festival Road and Muhammed Buhari way. This corresponds to ARTERIAL S1 and ARTERIAL S3, respectively, in Figure 1.2. With respect to the four input links of the intersection, the direction from 
ARTERIAL S1 is identified as North while its opposite direction identified as South. Similarly, the direction from ARTERIAL S3 is identified as East while its opposite direction is identified as West. Furthermore, Table 1.1 reports the fixed signal-timing plan that is currently implemented in the Cross-type intersection. In particular, the streams allowed to proceed during the phases of the signal timing plan in Table 1.1 are depicted in Figure 1.3 and labelled with letters corresponding to those indicated in Figure 1.2 and Table 1.1. More precisely, vehicle streams are represented with letters from $\mathrm{A}$ to $\mathrm{H}$, while pedestrian streams are not included. Moreover, amber (i.e.yellow) and intergreen times are taken into account in this case, so that the considered fixed timing plan comprises 23 phases, including two amber phases (i.e., phases 10 and 11) and one lost time phase (i.e., phase 12).

Modelling the Cross-type Intersection: The proposed Timed Coloured Petri Net (TCPN) model of the Cross-type intersection under consideration is developed consisting of two parts, namely the intersection sub-model and the traffic light submodels. Based on the Timed Coloured Petri Net formalism, the tokens required for both intersection and traffic light sub-models comprise three elements. The token elements (i.e. $i, t$ and $n$ ) and their interpretations are as enumerated:

- $\quad$ The element $i$ denotes the incoming vehicles into the cross-type intersection (i.e. stream $A_{T}, B_{T}, C_{L}, D_{L}, E_{T}, F_{T}, G_{L}, H_{L}, M_{R}, N_{R}, O_{R}, P_{R}$ vehicles).

- The element $t$ represents the average time interval of vehicles entering the cross-type intersection through each stream during green phase of each cycle.

- $\quad$ The element $n$ represents a counter counting the number of vehicles entering or leaving the cross-type intersection.

However, the parameters necessary to describe the traffic behaviours in the Cross-type intersection are as follows:

- The number of vehicles entering the intersection during green duration of each stream is measured by detectors positioned at each input link of the Cross-type intersection.
- The phase durations (in seconds) of green, red and yellow signal lights of each stream as reported in signal timing plan shown in Table 1.1.

The Intersection Sub-model of the Cross-type Intersection: Traffic light signals are an important mechanism applied to solve intersection conflicts and regulate traffic flow. To keep traffic flowing smoothly and safely, the intersection part of the proposed TCPN model is designed to model the vehicles passing through the Cross-type intersection under consideration, following the fixed signal timing plan depicted in Table 1.1. In particular, vehicles are allowed to enter the intersection through a particular input link when the signal light controlling the input link turns green.

However, the Intersection Sub-model requires five major places (to be drawn as circles and named Avgt, DATABASE, $V r, V i$ and $P$ ), two transitions (to be drawn as rectangular boxes and named Movi and Movo, a number of directed arcs connecting places and transitions, and finally some textual inscriptions next to the places (i.e. NI and IT) and arcs (e.g. (n, i) and $(i, t)$ ). By considering the firing sequence of the two transitions (Movi and Movo), the presence of tokens in the aforementioned places are defined as follows:

- A token in place Avgt represents the average time interval of vehicles entering the Crosstype intersection with respect to a particular stream.

- A token in place $V r$ means a vehicle ready to enter the Cross-type intersection.

- Place Vi with a token means a vehicle passing through the Cross-type intersection.

- Place $P$ with a token means a vehicle ready to enter the Cross-type intersection when the green signal light turns on in the first or second instances.

- Tokens in place DATABASE represent outgoing vehicles departing the Cross-type intersection.

Nevertheless, the transition Movi moves an incoming vehicle into the cross-type intersection while the transition Movo moves an outgoing vehicle out of the Cross-type intersection. 


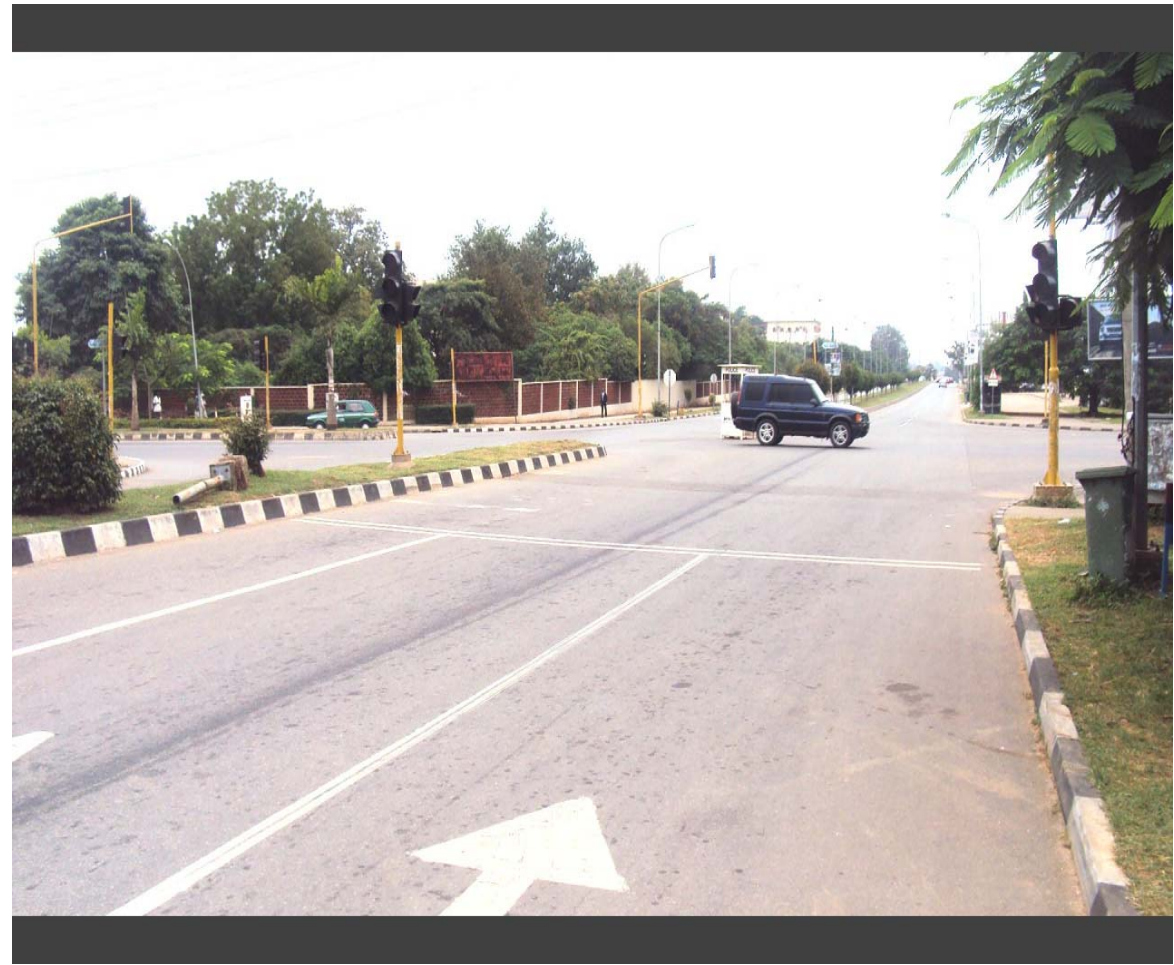

Fig 1.1: Snapshot of a Cross-type intersection located in FCT, Abuja, Nigeria.

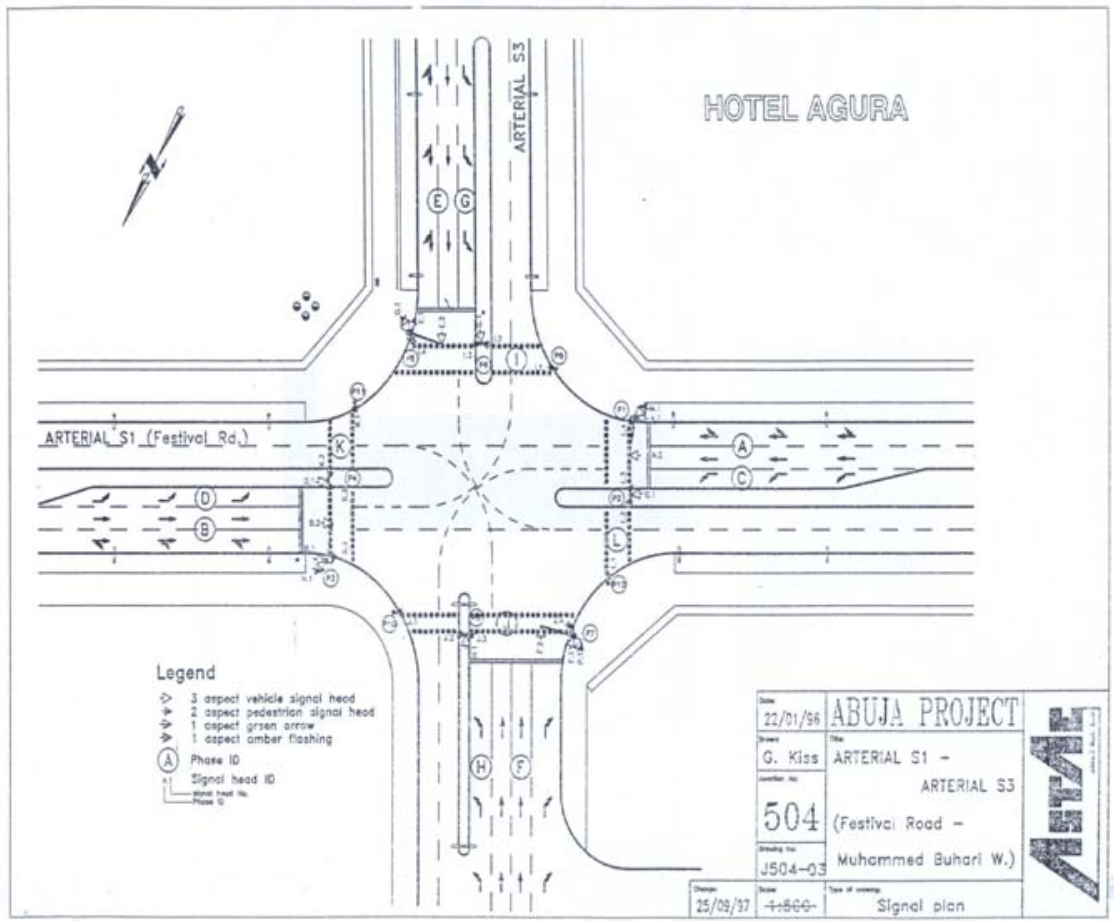

Fig 1.2: Layout of the Cross-type intersection depicted in Figure 1.1 
Am. J. Sci. Ind. Res., 2011, 2(5): 807-819

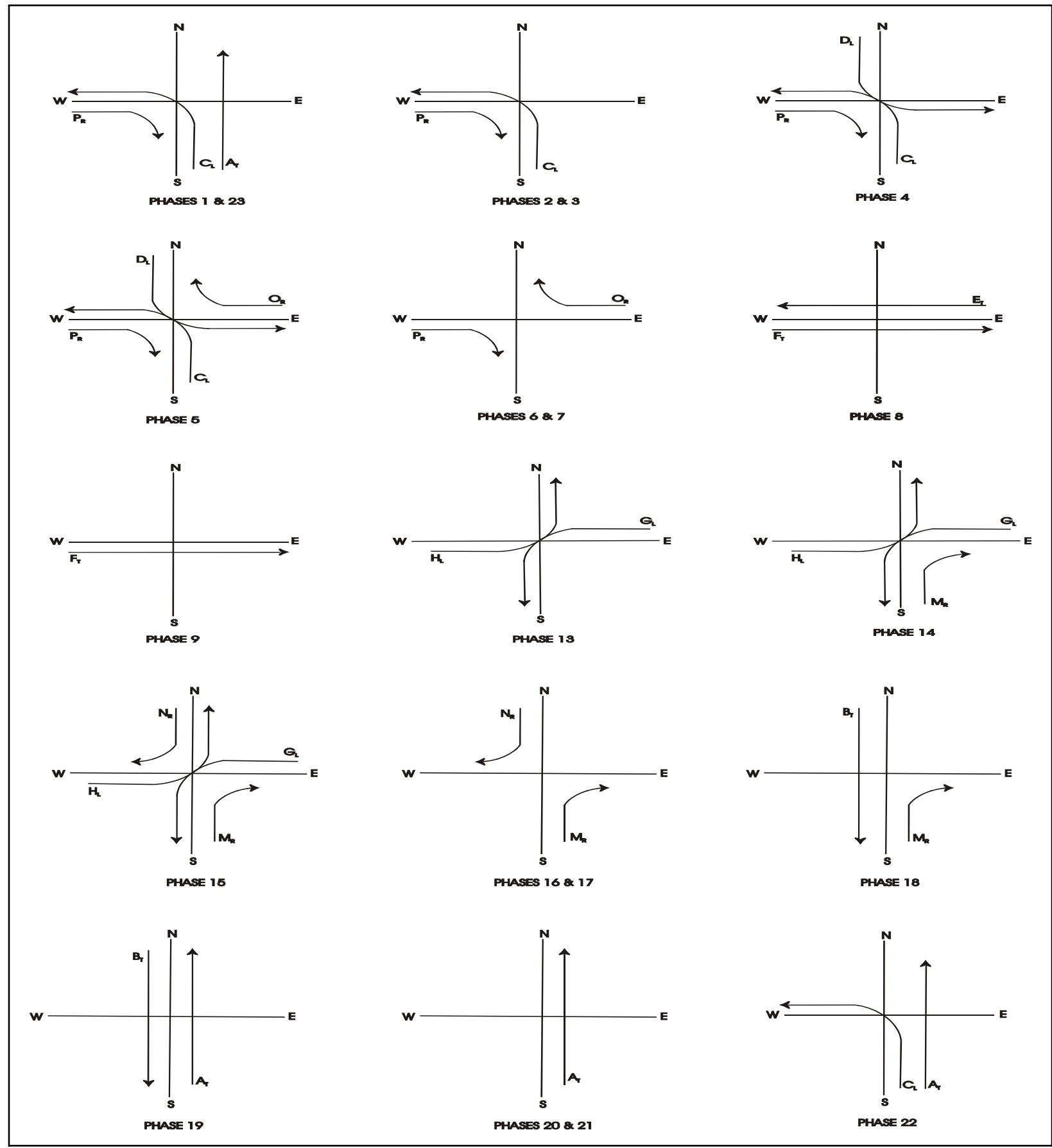

Fig 1.3: Vehicle streams in each phase of the signal timing plan of the Cross-type intersection 
Am. J. Sci. Ind. Res., 2011, 2(5): 807-819

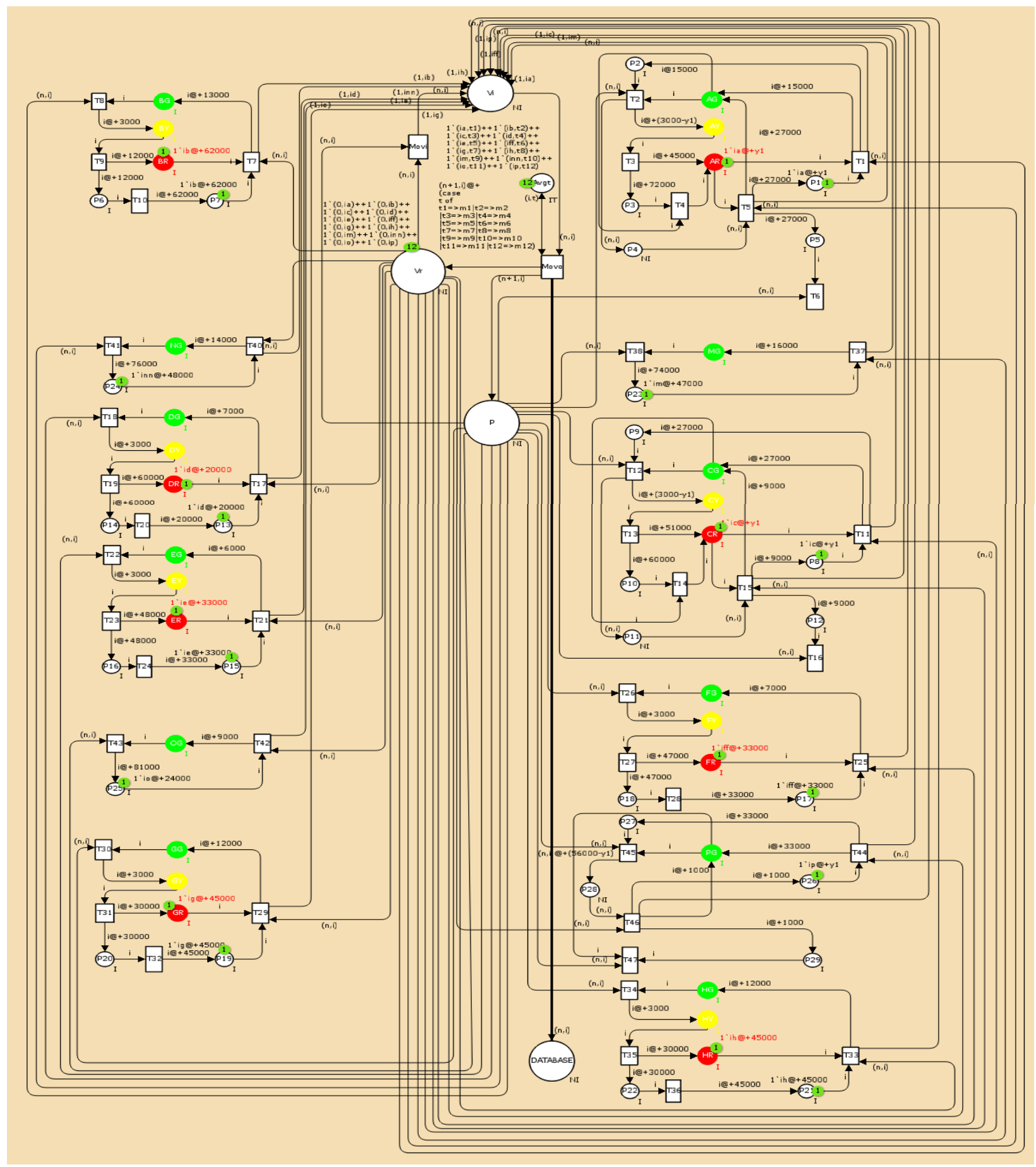

Fig 1.4: The developed TCPN model of the Cross-type intersection 
Am. J. Sci. Ind. Res., 2011, 2(5): 807-819

Table 1.1: Signal timing plan of the Cross-type intersection

\begin{tabular}{|c|c|c|c|c|c|c|c|c|c|c|c|c|c|c|c|c|c|c|c|c|c|c|c|c|}
\hline \multirow{2}{*}{ Streams } & \multirow{2}{*}{$\begin{array}{l}\text { Signal } \\
\text { Heads }\end{array}$} & \multicolumn{23}{|c|}{ Phases } \\
\hline & & 1 & 2 & 3 & 4 & 5 & 6 & 7 & 8 & 9 & $\begin{array}{l}1 \\
0\end{array}$ & $\begin{array}{l}1 \\
1 \\
\end{array}$ & $\begin{array}{l}1 \\
2\end{array}$ & $\begin{array}{l}1 \\
3\end{array}$ & $\begin{array}{l}1 \\
4 \\
\end{array}$ & $\begin{array}{l}1 \\
5\end{array}$ & $\begin{array}{l}1 \\
6\end{array}$ & $\begin{array}{l}1 \\
7\end{array}$ & $\begin{array}{l}1 \\
8 \\
\end{array}$ & $\begin{array}{l}1 \\
9 \\
\end{array}$ & $\begin{array}{l}2 \\
0\end{array}$ & $\begin{array}{l}2 \\
1 \\
\end{array}$ & $\begin{array}{l}2 \\
2 \\
\end{array}$ & $\begin{array}{l}2 \\
3 \\
\end{array}$ \\
\hline$A_{T}$ & A.1 A. 2 & G & $Y$ & $\mathrm{R}$ & $\mathrm{R}$ & $\mathrm{R}$ & $\mathrm{R}$ & $\mathrm{R}$ & $\mathrm{R}$ & $\mathrm{R}$ & $\mathrm{R}$ & $\mathrm{R}$ & $\mathrm{R}$ & $\mathrm{R}$ & $\mathrm{R}$ & $\mathrm{R}$ & $\mathrm{R}$ & $\mathrm{R}$ & $\mathrm{R}$ & $G$ & $G$ & $G$ & $G$ & G \\
\hline $\mathrm{B}_{\mathrm{T}}$ & B.1 B.2 & $\mathrm{R}$ & $\mathrm{R}$ & $R$ & $R$ & $\mathrm{R}$ & $\mathrm{R}$ & $\mathrm{R}$ & $R$ & $\mathrm{R}$ & $\mathrm{R}$ & $\mathrm{R}$ & $\mathrm{R}$ & $\mathrm{R}$ & $\mathrm{R}$ & $\mathrm{R}$ & $\mathrm{R}$ & $\mathrm{R}$ & G & G & $Y$ & $\mathrm{R}$ & $\mathrm{R}$ & $\mathrm{R}$ \\
\hline$C_{L}$ & C.1 & G & G & $\mathrm{G}$ & G & G & $Y$ & $\mathrm{R}$ & $\mathrm{R}$ & $\mathrm{R}$ & $\mathrm{R}$ & $\mathrm{R}$ & $\mathrm{R}$ & $\mathrm{R}$ & $\mathrm{R}$ & $\mathrm{R}$ & $\mathrm{R}$ & $\mathrm{R}$ & $\mathrm{R}$ & $\mathrm{R}$ & $\mathrm{R}$ & $\mathrm{R}$ & $G$ & G \\
\hline $\mathrm{D}_{\mathrm{L}}$ & D.1 & $\mathrm{R}$ & $\mathrm{R}$ & $\mathrm{R}$ & $G$ & $G$ & $\mathrm{Y}$ & $\mathrm{R}$ & $\mathrm{R}$ & $\mathrm{R}$ & $\mathrm{R}$ & $\mathrm{R}$ & $\mathrm{R}$ & $\mathrm{R}$ & $\mathrm{R}$ & $\mathrm{R}$ & $\mathrm{R}$ & $\mathrm{R}$ & $\mathrm{R}$ & $\mathrm{R}$ & $\mathrm{R}$ & $\mathrm{R}$ & $\mathrm{R}$ & $\mathrm{R}$ \\
\hline $\mathrm{E}_{\mathrm{T}}$ & E.1 E.2 & $\mathrm{R}$ & $\mathrm{R}$ & $\mathrm{R}$ & $\mathrm{R}$ & $\mathrm{R}$ & $\mathrm{R}$ & $\mathrm{R}$ & G & $Y$ & $Y$ & $\mathrm{R}$ & $\mathrm{R}$ & $\mathrm{R}$ & $\mathrm{R}$ & $\mathrm{R}$ & $\mathrm{R}$ & $\mathrm{R}$ & $\mathrm{R}$ & $\mathrm{R}$ & $\mathrm{R}$ & $\mathrm{R}$ & $\mathrm{R}$ & $\mathrm{R}$ \\
\hline $\mathrm{F}_{\mathrm{T}}$ & F.1 F.2 & $\mathrm{R}$ & $\mathrm{R}$ & $R$ & $\mathrm{R}$ & $\mathrm{R}$ & $\mathrm{R}$ & $\mathrm{R}$ & G & G & $\mathrm{Y}$ & $\mathrm{Y}$ & $\mathrm{R}$ & $\mathrm{R}$ & $\mathrm{R}$ & $\mathrm{R}$ & $\mathrm{R}$ & $\mathrm{R}$ & $\mathrm{R}$ & $\mathrm{R}$ & $\mathrm{R}$ & $\mathrm{R}$ & $\mathrm{R}$ & $\mathrm{R}$ \\
\hline $\mathrm{G}_{\mathrm{L}}$ & G.1 & $\mathrm{R}$ & $\mathrm{R}$ & $\mathrm{R}$ & $\mathrm{R}$ & $\mathrm{R}$ & $\mathrm{R}$ & $\mathrm{R}$ & $\mathrm{R}$ & $\mathrm{R}$ & $\mathrm{R}$ & $\mathrm{R}$ & $\mathrm{R}$ & G & G & G & $Y$ & $\mathrm{R}$ & $\mathrm{R}$ & $\mathrm{R}$ & $\mathrm{R}$ & $\mathrm{R}$ & $\mathrm{R}$ & $\mathrm{R}$ \\
\hline $\mathrm{H}_{\mathrm{L}}$ & H.1 & $\mathrm{R}$ & $\mathrm{R}$ & $\mathrm{R}$ & $\mathrm{R}$ & $\mathrm{R}$ & $\mathrm{R}$ & $\mathrm{R}$ & $\mathrm{R}$ & $\mathrm{R}$ & $\mathrm{R}$ & $\mathrm{R}$ & $\mathrm{R}$ & G & G & G & Y & $\mathrm{R}$ & $\mathrm{R}$ & $\mathrm{R}$ & $\mathrm{R}$ & $\mathrm{R}$ & $\mathrm{R}$ & $\mathrm{R}$ \\
\hline$M_{R}$ & M.1 & & & & & & & & & & & & & & G & G & G & G & G & & & & & \\
\hline $\mathrm{N}_{\mathrm{R}}$ & N.I & & & & & & & & & & & & & & & G & G & G & & & & & & \\
\hline $\mathrm{O}_{\mathrm{R}}$ & 0.1 & & & & & G & G & G & & & & & & & & & & & & & & & & \\
\hline$P_{R}$ & P.1 & G & G & G & G & G & G & G & & & & & & & & & & & & & & & & G \\
\hline \multicolumn{2}{|c|}{$\begin{array}{c}\text { Phase Duration } \\
\text { (sec) }\end{array}$} & $\begin{array}{l}1 \\
5\end{array}$ & 3 & 2 & 4 & 3 & 3 & 3 & 6 & 1 & 2 & 1 & 2 & 2 & 1 & 9 & 3 & 2 & 1 & $\begin{array}{l}1 \\
2\end{array}$ & 3 & 3 & 8 & 1 \\
\hline \multicolumn{2}{|c|}{ Cycle Duration (sec) } & \multicolumn{23}{|c|}{90} \\
\hline
\end{tabular}

Legend G: Green signal

The Traffic Light Sub-models of the Cross-type Intersection: To correctly control an intersection via traffic light signal indications, each traffic signal must follow a defined sequence of active colour lights, normally from green to yellow and red, and then backing to green. As a result, the traffic light part of the proposed TCPN model modelled the changing rule of traffic lights according to the fixed signaltiming plan shown in Table 1.1. In particular, vehicles are allowed to pass through an intersection when green lights are turned on. On the other hand, vehicles are inhibited to pass through an intersection during red and yellow signal indications as these, in Nigerian context, correspond to stop and stop at the stop line, respectively.

By considering the Cross-type intersection shown in Figure 1.2, there are twelve vehicle streams identified, namely C-left, D-left, G-left, H-left, M-right, $\mathrm{N}$-right, O-right, P-right, A-through, B-through, Ethrough and $F$-through denoted by $C_{L}, D_{L}, G_{L}, H_{L}, M_{R}$, $N_{R}, O_{R}, P_{R}, A_{T}, B_{T}, E_{T}$ and $F_{T}$, respectively. As a result, the traffic light part of the TCPN modelling the Cross-type intersection would be divided into twelve sub-models. These are called streams $C_{L}, D_{L}, G_{L}, H_{L}$, $M_{R}, N_{R}, O_{R}, P_{R}, A_{T}, B_{T}, E_{T}$ and $F_{T}$ sub-models. Each of the first four streams (i.e. $C_{L}, D_{L}, G_{L}$ and $H_{L}$ ) is controlled by one set of traffic light (i.e. Red, Yellow and Green signal lights) while each of the next four streams (i.e. $M_{R}, N_{R}, O_{R}$ and $P_{R}$ ) is controlled only by a Right turn green arrow light.

However, the last four streams (i.e. $A_{T}, B_{T}, E_{T}$ and $F_{T}$ ) are individually controlled by two sets of traffic lights. To be precise, each of the last four streams is allocated two lanes and controlled correspondingly by two sets of traffic lights placed on a long arm cantilever. As an example, two sets of traffic lights represented by $A .1$ and A.2 in Figure 1.2 concurrently control the Stream $A_{T}$ vehicles. As reflected by signal heads depicted in Table 1.1, in modelling stream $A_{T}$ traffic lights, the two sets of traffic lights would be merged and represented as follows:

- Place $A_{G}$ models the state of green light controlling the Stream $A_{T}$ vehicles

- Place $A_{Y}$ models the state of yellow light controlling the Stream $A_{T}$ vehicles

- Place $A_{R}$ models the state of red light controlling the Stream $A_{T}$ vehicles

This is also applicable to the two sets of traffic lights ruling each of the streams $\mathrm{B}_{\mathrm{T}}, \mathrm{E}_{\mathrm{T}}$ and $\mathrm{F}_{\mathrm{T}}$. That is, the two sets of traffic lights controlling each of these streams would be merged and modelled as stated in Table 1.2. Besides, the model representations of the other traffic lights (i.e. streams $C_{L}, D_{L}, G_{L}, H_{L}, M_{R}, N_{R}$, $\mathrm{O}_{R}$ and $\mathrm{P}_{\mathrm{R}}$ traffic lights) are also explicated in Table 1.2. Moreover, taking model representation of the stream $A_{T}$ traffic lights as an example, the presence 
of token in each of the places $A_{G}, A_{Y}$ and $A_{R}$ means green, yellow and red signal lights turn on respectively, and turn off otherwise. This is also applicable for each of the streams $C_{L}, D_{L}, G_{L}, H_{L}, M_{R}$, $\mathrm{N}_{\mathrm{R}}, \mathrm{O}_{\mathrm{R}}, \mathrm{P}_{\mathrm{R}}, \mathrm{B}_{\mathrm{T}}, \mathrm{E}_{\mathrm{T}}$ and $\mathrm{F}_{\mathrm{T}}$ traffic lights.

Table 1.2: Model Representation of Major Traffic Light States of the Cross-type Intersection

\begin{tabular}{|c|c|c|}
\hline Sub-models & Places & Model Representations \\
\hline \multirow{3}{*}{ Stream $B_{T}$} & $\mathrm{~B}_{\mathrm{G}}$ & Models the state of green light controlling the Stream $\mathrm{B}_{\mathrm{T}}$ vehicles. \\
\hline & $\mathrm{B}_{\mathrm{Y}}$ & Models the state of yellow light controlling the Stream $\mathrm{B}_{\mathrm{T}}$ vehicles. \\
\hline & $\mathrm{B}_{\mathrm{R}}$ & Models the state of red light controlling the Stream $\mathrm{B}_{\mathrm{T}}$ vehicles. \\
\hline \multirow{3}{*}{ Stream $\mathrm{E}_{\mathrm{T}}$} & $E_{G}$ & Models the state of green light controlling the Stream $\mathrm{E}_{\mathrm{T}}$ vehicles. \\
\hline & $E_{Y}$ & Models the state of yellow light controlling the Stream $\mathrm{E}_{\mathrm{T}}$ vehicles. \\
\hline & $E_{R}$ & Models the state of red light controlling the Stream $\mathrm{E}_{\mathrm{T}}$ vehicles. \\
\hline \multirow{3}{*}{ Stream $\mathrm{F}_{\mathrm{T}}$} & $\mathrm{F}_{\mathrm{G}}$ & Models the state of green light controlling the Stream $\mathrm{F}_{\mathrm{T}}$ vehicles. \\
\hline & $\mathrm{F}_{\mathrm{Y}}$ & Models the state of yellow light controlling the Stream $\mathrm{F}_{\mathrm{T}}$ vehicles. \\
\hline & $\mathrm{F}_{\mathrm{R}}$ & Models the state of red light controlling the Stream $\mathrm{F}_{\mathrm{T}}$ vehicles. \\
\hline \multirow{3}{*}{ Stream $C_{L}$} & $\mathrm{C}_{\mathrm{G}}$ & Models the state of green light controlling the Stream $C_{L}$ vehicles. \\
\hline & $\mathrm{C}_{Y}$ & Models the state of yellow light controlling the Stream $C_{L}$ vehicles. \\
\hline & $\mathrm{C}_{\mathrm{R}}$ & Models the state of red light controlling the Stream $C_{L}$ vehicles. \\
\hline \multirow{3}{*}{ Stream $D_{L}$} & $\mathrm{D}_{\mathrm{G}}$ & Models the state of green light controlling the Stream $D_{L}$ vehicles. \\
\hline & $D_{Y}$ & Models the state of yellow light controlling the Stream $D_{L}$ vehicles. \\
\hline & $\mathrm{D}_{\mathrm{R}}$ & Models the state of red light controlling the Stream $\mathrm{D}_{\mathrm{L}}$ vehicles. \\
\hline \multirow{3}{*}{ Stream $G_{L}$} & $\mathrm{G}_{\mathrm{G}}$ & Models the state of green light controlling the Stream $\mathrm{G}_{\mathrm{L}}$ vehicles. \\
\hline & $\mathrm{G}_{Y}$ & Models the state of yellow light controlling the Stream $\mathrm{G}_{\mathrm{L}}$ vehicles. \\
\hline & $\mathrm{G}_{\mathrm{R}}$ & Models the state of red light controlling the Stream $\mathrm{G}_{\mathrm{L}}$ vehicles. \\
\hline \multirow{3}{*}{ Stream $\mathrm{H}_{\mathrm{L}}$} & $\mathrm{H}_{\mathrm{G}}$ & Models the state of green light controlling the Stream $\mathrm{H}_{\mathrm{L}}$ vehicles. \\
\hline & $\mathrm{H}_{\mathrm{Y}}$ & Models the state of yellow light controlling the Stream $\mathrm{H}_{\mathrm{L}}$ vehicles. \\
\hline & $\mathrm{H}_{\mathrm{R}}$ & Models the state of red light controlling the Stream $\mathrm{H}_{\mathrm{L}}$ vehicles. \\
\hline Stream $\mathrm{M}_{\mathrm{R}}$ & $\mathrm{M}_{\mathrm{G}}$ & Models the state of a Right turn green arrow light controlling the stream $M_{R}$ vehicles. \\
\hline Stream $\mathrm{N}_{\mathrm{R}}$ & $\mathrm{N}_{\mathrm{G}}$ & Models the state of a Right turn green arrow light controlling the stream $\mathrm{N}_{\mathrm{R}}$ vehicles. \\
\hline Stream $\mathrm{O}_{\mathrm{R}}$ & $\mathrm{O}_{\mathrm{G}}$ & Models the state of a Right turn green arrow light controlling the stream $\mathrm{O}_{\mathrm{R}}$ vehicles. \\
\hline Stream $P_{R}$ & $\mathrm{P}_{\mathrm{G}}$ & Models the state of a Right turn green arrow light controlling the stream $\mathrm{P}_{\mathrm{R}}$ vehicles. \\
\hline
\end{tabular}

Furthermore, for each of the twelve traffic light submodels, the transitions required and their functions are enumerated in Tables 1.3(a) and 1.3(b). Based on the rules of Timed Colored Petri Nets, all the transitions would be drawn as rectangles. These represent individual events taking place in the traffic lights of the Cross-type junction. As with places, the names of the transitions are written inside the rectangles (e.g. T1, T2, T3, etc). A number of directed arcs connecting places and transitions are associated with appropriate arc expressions which consist of one or two of the following decision variables:
- $\quad$ Element $i$ denoting the incoming vehicles into the Cross-type intersection (i.e. incoming vehicles along streams $C_{L}, D_{L}, G_{L}, H_{L}, M_{R}$, $\mathrm{N}_{\mathrm{R}}, \mathrm{O}_{\mathrm{R}}, \mathrm{P}_{\mathrm{R}}, \mathrm{A}_{\mathrm{T}}, \mathrm{B}_{\mathrm{T}}, \mathrm{E}_{\mathrm{T}}$ and $\mathrm{F}_{\mathrm{T}}$ would to be denoted by ic, id, ig, ih, im, inn, io, ip, ia, ib, ie and iff respectively).

- $\quad$ Element $n$ denoting a counter that counts the number of vehicles entering or leaving the Cross-type intersection.

- Time stamp derived from durations of green, red and yellow signal lights of each stream shown in Table 1.1. This would be introduced using the symbol @. It should be noted that 
the time stamp could be defined as seconds,

microseconds, milliseconds, etc, depending

on the choice of modeller.

Table 1.3(a): Major Transitions of the Twelve Traffic Light Sub-models

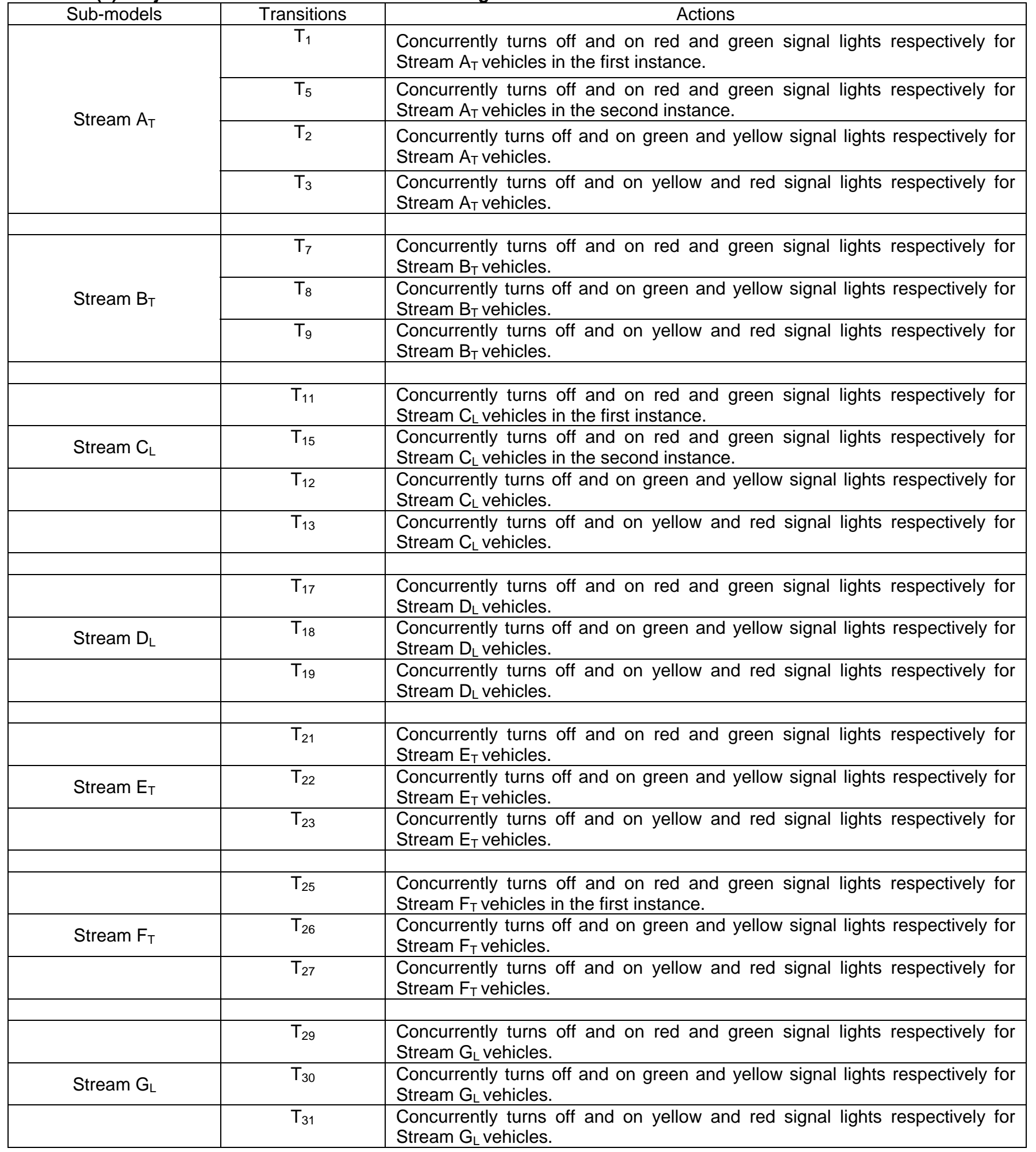


Table 1.3(b): Major Transitions of the Twelve Traffic Light Sub-models

\begin{tabular}{|c|c|c|}
\hline Sub-models & Transitions & Actions \\
\hline & $\mathrm{T}_{33}$ & $\begin{array}{l}\text { Concurrently turns off and on red and green signal lights respectively for } \\
\text { Stream } H_{L} \text { vehicles. }\end{array}$ \\
\hline \multirow[t]{2}{*}{ Stream $\mathrm{H}_{\mathrm{L}}$} & $\mathrm{T}_{34}$ & $\begin{array}{l}\text { Concurrently turns off and on green and yellow signal lights respectively } \\
\text { for Stream } H_{L} \text { vehicles. }\end{array}$ \\
\hline & $T_{35}$ & $\begin{array}{l}\text { Concurrently turns off and on yellow and red signal lights respectively for } \\
\text { Stream } H_{L} \text { vehicles. }\end{array}$ \\
\hline \multirow{2}{*}{ Stream $M_{R}$} & $T_{37}$ & Turns on a Right turn green arrow light for Stream $M_{R}$ vehicles. \\
\hline & $T_{38}$ & Turns off a Right turn green arrow light for Stream $M_{R}$ vehicles \\
\hline \multirow[t]{2}{*}{ Stream $N_{R}$} & $T_{40}$ & Turns on a Right turn green arrow light for Stream $N_{R}$ vehicles. \\
\hline & $\mathrm{T}_{41}$ & Turns off a Right turn green arrow light for Stream $N_{R}$ vehicles \\
\hline \multirow[t]{2}{*}{ Stream $O_{R}$} & $T_{42}$ & Turns on a Right turn green arrow light for Stream $O_{R}$ vehicles. \\
\hline & $\mathrm{T}_{43}$ & Turns off a Right turn green arrow light for Stream $O_{R}$ vehicles \\
\hline \multirow{3}{*}{ Stream $P_{R}$} & $\mathrm{~T}_{44}$ & Turns on a Right turn green arrow light for Stream $P_{R}$ vehicles. \\
\hline & $T_{45}$ & Turns off a Right turn green arrow light for Stream $P_{R}$ vehicles \\
\hline & $\mathrm{T}_{46}$ & $\begin{array}{l}\text { Turns on a Right turn green arrow light for Stream } P_{R} \text { vehicles in the } \\
\text { second instance. }\end{array}$ \\
\hline
\end{tabular}

Table 1.4(a): Average time interval of vehicles for streams $A_{T}, B_{T}, C_{L}, D_{L}, E_{T}$ and $F_{T}$

\begin{tabular}{|c|c|c|c|c|c|c|}
\hline Cycle & $\begin{array}{c}\text { Stream } \mathbf{A}_{\boldsymbol{T}} \\
\text { (millisecond) }\end{array}$ & $\begin{array}{c}\text { Stream } \mathbf{B}_{\mathbf{T}} \\
\text { (millisecond) }\end{array}$ & $\begin{array}{c}\text { Stream } \mathbf{C}_{\mathbf{L}} \\
\text { (millisecond) }\end{array}$ & $\begin{array}{c}\text { Stream } \mathbf{D}_{\mathbf{L}} \\
\text { (millisecond) }\end{array}$ & $\begin{array}{c}\text { Stream } \mathbf{E}_{\mathbf{T}} \\
\text { (millisecond) }\end{array}$ & $\begin{array}{c}\text { Stream } \mathbf{F}_{\mathbf{T}} \\
\text { (millisecond) }\end{array}$ \\
\hline 1 & 14000 & 6500 & 36000 & 3500 & 2000 & 7000 \\
\hline 2 & 5250 & 2167 & 18000 & 1400 & 1000 & 2333 \\
\hline 3 & 3818 & 1300 & 12000 & 1000 & 667 & 2333 \\
\hline 4 & 3500 & 1000 & 12000 & 875 & 545 & 1750 \\
\hline 5 & 3818 & 867 & 18000 & 538 & 429 & 1750 \\
\hline 6 & 6000 & 1083 & 36000 & 538 & 545 & 1750 \\
\hline 7 & 3500 & 1300 & 18000 & 778 & 500 & 1167 \\
\hline 8 & 2471 & 1083 & 9000 & 875 & 545 & 1000 \\
\hline 9 & 2333 & 813 & 7200 & 1167 & 462 & 1400 \\
\hline 10 & 2625 & 1182 & 18000 & 1400 & 500 & 2333 \\
\hline 11 & 3000 & 1182 & 18000 & 1400 & 545 & 1750 \\
\hline 12 & 3500 & 867 & 36000 & 636 & 545 & 1750 \\
\hline 13 & 2333 & 1444 & 36000 & 1000 & 600 & 1167 \\
\hline 14 & 3500 & 2167 & 36000 & 1750 & 857 & 1750 \\
\hline 15 & 6000 & 6500 & 36000 & 1750 & 1500 & 2333 \\
\hline
\end{tabular}


Am. J. Sci. Ind. Res., 2011, 2(5): 807-819

Table 1.4(b): Average time interval of vehicles for streams $G_{L}, H_{L}, M_{R}, N_{R}, O_{R}$ and $P_{R}$

\begin{tabular}{|c|c|c|c|c|c|c|}
\hline Cycle & $\begin{array}{c}\text { Stream } \mathbf{G}_{\mathbf{L}} \\
\text { (millisecond) }\end{array}$ & $\begin{array}{c}\text { Stream } \mathbf{H}_{\mathbf{L}} \\
\text { (millisecond) }\end{array}$ & $\begin{array}{c}\text { Stream } \mathbf{M}_{\mathbf{R}} \\
\text { (millisecond) }\end{array}$ & $\begin{array}{c}\text { Stream } \mathbf{N}_{\mathbf{R}} \\
\text { (millisecond) }\end{array}$ & $\begin{array}{c}\text { Stream } \mathbf{O}_{\mathbf{R}} \\
\text { (millisecond) }\end{array}$ & $\begin{array}{c}\text { Stream } \mathbf{P}_{\mathbf{R}} \\
(\mathbf{m i l l i s e c o n d )}\end{array}$ \\
\hline 1 & 4000 & 12000 & 5333 & 14000 & 3000 & 34000 \\
\hline 2 & 1200 & 12000 & 1778 & 14000 & 2250 & 34000 \\
\hline 3 & 750 & 12000 & 1143 & 14000 & 1800 & 34000 \\
\hline 4 & 480 & 12000 & 941 & 7000 & 2250 & 34000 \\
\hline 5 & 414 & 12000 & 727 & 4667 & 1500 & 34000 \\
\hline 6 & 571 & 12000 & 941 & 7000 & 1800 & 34000 \\
\hline 7 & 632 & 12000 & 615 & 7000 & 2250 & 34000 \\
\hline 8 & 750 & 12000 & 471 & 14000 & 1800 & 34000 \\
\hline 9 & 545 & 6000 & 1067 & 3500 & 2250 & 34000 \\
\hline 10 & 750 & 12000 & 1231 & 14000 & 1800 & 34000 \\
\hline 11 & 1000 & 6000 & 1333 & 7000 & 1800 & 17000 \\
\hline 12 & 571 & 6000 & 842 & 7000 & 1125 & 34000 \\
\hline 13 & 857 & 6000 & 762 & 14000 & 1800 & 34000 \\
\hline 14 & 1333 & 12000 & 1143 & 14000 & 1800 & 34000 \\
\hline 15 & 2400 & 12000 & 1600 & 14000 & 2250 & 34000 \\
\hline
\end{tabular}

Assumptions Made in the TCPN model of the Cross-type Intersection: In the development of the Timed Coloured Petri Net model for the Cross-type intersection under consideration, the following assumptions are made:

- $\quad$ One time stamp unit is assumed to represent one millisecond in the TCPN model.

- The model execution is assumed to begin when the model time (i.e. global clock) reaches one millisecond.

Simulation of the Developed TCPN Model: The developed Timed Coloured Petri Net Model of the Cross-type intersection is simulated using CPN tools (Version 3.0.2). CPN Tools is a tool suite for editing, simulation and performance analysis of CPN models. The user of CPN Tools works directly on the graphical representation of the TCPN model. The graphical user interface (GUI) of CPN Tools has no conventional menu bars and pull-down menus, but is based on interaction techniques such as tool palettes and marking menus. For this simulation work, the average time interval of vehicles entering the crosstype intersection with respect to a particular stream during green phase of each cycle is required by the CPN tools. Through the use of detectors, the data is obtained at the Cross-type intersection under consideration. Precisely, the data is collected for fifteen cycles of the green duration between 6:00am and 4:00pm in one day. The average time interval of vehicles for each cycle through each stream is as approximated and shown in Tables 1.4(a) and 1.4(b).

\section{RESULTS AND DISCUSSION}

Figure 1.4 shows the developed Timed Coloured Petri Net model of the Cross-type intersection under consideration. However, the developed TCPN model of the Cross-type intersection is characterized by the following:

- Eight sets of traffic lights controlling the stream $A_{T}, B_{T}, C_{L}, D_{L}, E_{T}, F_{T}, G_{L}$ and $H_{L}$ vehicles and four right-turn green arrow lights controlling the stream $M_{R}, N_{R}, O_{R}$ and $P_{R}$ vehicles.

- One intersection sub-model and twelve traffic light sub-models (i.e. streams $A_{T}, B_{T}, C_{L}, D_{L}$, $E_{T}, F_{T}, G_{L}, H_{L}, M_{R}, N_{R}, O_{R}$ and $P_{R}$ submodels) that allow easy model modification or development for other related multi-phase traffic light controlled Cross-type intersection.

- $\quad$ The modelling of lost time phases (i.e. phase 12) and repeated phases (i.e. phases 1 and 23) embodied within a complete cycle of the fixed signal timing plans of the Cross-type intersection.

- The incorporation of a report place named DATABASE, which records the results of the simulation of the Cross-type intersection model. Precisely, the place DATABASE lists all vehicles that cross the Cross-type intersection along each of the vehicle 
Am. J. Sci. Ind. Res., 2011, 2(5): 807-819

streams $A_{T}, B_{T}, C_{L}, D_{L}, E_{T}, F_{T}, G_{L}, H_{L}, M_{R}$, $N_{R}, O_{R}$ and $P_{R}$, and the time at which they cross the intersection during the simulation of the developed model via CPN Tools.

- The presence of tokens in the places $A R$, BR, CR, DR, ER, FR, GR, HR, P1, P7, P8, P13, P15, P17, P19, P21, P23, P24, P25, $P 26$, Avgt and $V r$ which constitutes the initial marking or lost time phase of the model.

Furthermore, Table 1.5 depicts the simulated traffic volume through each of the four input links of the Cross-type intersection under consideration during the fifteen cycles. Out of the total simulated number of vehicles crossing the Cross-type intersection through its four input links, Festival Road From South experienced the highest traffic congestion with $35.1 \%$ traffic volume, followed by Muhammed Buhari Way From East with 34.3\% traffic volume, followed by Festival Road From North with $21.6 \%$ traffic volume while Muhammed Buhari Way From West experienced the least traffic congestion with 9\% traffic volume. In particular, for each of the fifteen cycles, the simulated and the measured numbers of vehicles passing through the Cross-type intersection along each stream are the same in the best case while the difference of at most one is recorded between the former and the latter in the worst case. Statistically, during the fifteen cycles, as shown in Table 1.6, there were no significant differences between the simulated and the measured numbers of vehicles crossing the Cross-type intersection through its four input links at 5\% level. Thus, the simulation results are consistent with the measured traffic data.

Table 1.5: Simulated Traffic Volumes through the Four Input Links of the Cross-type Intersection

\begin{tabular}{|c|c|c|c|}
\hline Input Link & Streams & $\begin{array}{c}\text { Total } \\
\text { Simulated } \\
\text { Number of } \\
\text { Vehicles }\end{array}$ & $\begin{array}{c}\text { Traffic } \\
\text { Volume }\end{array}$ \\
\hline $\begin{array}{c}\text { Festival Road } \\
\text { From South }\end{array}$ & $\mathrm{A}_{\mathrm{T}}, \mathrm{C}_{\mathrm{L}}, \mathrm{M}_{\mathrm{R}}$ & 490 & $35.1 \%$ \\
\hline $\begin{array}{c}\text { Festival Road } \\
\text { From North }\end{array}$ & $\mathrm{B}_{\mathrm{T}}, \mathrm{D}_{\mathrm{L}}, \mathrm{N}_{\mathrm{R}}$ & 302 & $21.6 \%$ \\
\hline $\begin{array}{c}\text { Muhammed } \\
\text { Buhari Way } \\
\text { From East }\end{array}$ & $\mathrm{E}_{\mathrm{T}}, \mathrm{G}_{\mathrm{L}}, \mathrm{O}_{\mathrm{R}}$ & 479 & $34.3 \%$ \\
\hline $\begin{array}{c}\text { Muhammed } \\
\text { Buhari Way } \\
\text { From West }\end{array}$ & $\mathrm{F}_{\mathrm{T}}, \mathrm{H}_{\mathrm{L}}, \mathrm{P}_{\mathrm{R}}$ & 125 & $9 \%$ \\
\hline
\end{tabular}

Table 1.6: Summary of t-test for the Simulation Results and the Measured Traffic Data of the Cross-type Intersection

\begin{tabular}{|c|c|c|c|}
\hline Variable & t-value & p- & Remark \\
\hline $\begin{array}{l}\text { Festival Road From } \\
\text { South Simulated - } \\
\text { Festival Road From } \\
\text { South Measured }\end{array}$ & $14.642^{*}$ & 0.000 & $\begin{array}{l}\text { No } \\
\text { Significant } \\
\text { Difference }\end{array}$ \\
\hline $\begin{array}{l}\text { Festival Road From } \\
\text { North Simulated - } \\
\text { Festival Road From } \\
\text { North Measured }\end{array}$ & $6.874^{\pi}$ & 0.000 & $\begin{array}{c}\text { No } \\
\text { Significant } \\
\text { Difference }\end{array}$ \\
\hline $\begin{array}{lr}\text { Muhammed } & \text { Buhari } \\
\text { Way From } & \text { East } \\
\text { Simulated } & - \\
\text { Muhammed } & \text { Buhari } \\
\text { Way From } & \text { East } \\
\text { Measured } & \\
\end{array}$ & $6.287^{*}$ & 0.000 & $\begin{array}{c}\text { No } \\
\text { Significant } \\
\text { Difference }\end{array}$ \\
\hline $\begin{array}{lr}\text { Muhammed } & \text { Buhari } \\
\text { Way From } & \text { West } \\
\text { Simulated } & - \\
\text { Muhammed } & \text { Buhari } \\
\text { Way From } & \text { West } \\
\text { Measured } & \\
\end{array}$ & $9.374^{*}$ & 0.000 & $\begin{array}{c}\text { No } \\
\text { Significant } \\
\text { Difference }\end{array}$ \\
\hline
\end{tabular}

* No Significant Difference at $p<0.05$ CONCLUSIONS:

This research work has been able to develop and validate Timed Coloured Petri Net (TCPN) model of real intersection using a multi-phase traffic light controlled Cross-type intersection of fixed signal timing plan located in Federal Capital Territory, Abuja, Nigeria, as a case study. The developed Timed Coloured Petri Net (TCPN) model is able to provide a valid representation of the considered cross-type intersection based on the result of the statistical analysis, which shows that there were no significant differences between the simulated and the measured numbers of vehicles crossing the Crosstype intersection at 5\% level. Thus, the simulation results give a confirmation of the developed TCPN model's efficacy to correctly describe the traffic behavior in the Cross-type intersection under consideration.

In addition, the developed TCPN model could help in studying and improving traffic flow for a platoon of vehicles in the Cross-type intersection under consideration. By varying the measured number of vehicles passing through the intersection along each stream, traffic flow can be improved based on the new knowledge, in respect of traffic behaviour, to be acquired during the simulation of the aforementioned model. Besides, the result of this work could serve as a basis for setting real-time actuated signal controller for the modelled scenario and allow easy model 
development for other related multiphase traffic light control intersections through its vehicle stream submodels.

Furthermore, future and further research may be geared towards developing a Timed Coloured Petri Net model for the multi-phase traffic light controlled cross-type intersection characterized by a traffic response control strategy. Also, the occurrence graph (O-graph), as one of the analysis methods of Timed Coloured Petri Net models, could be used to verify the safeness and liveness properties associated with the developed TCPN model.

\section{REFERENCES}

Dotoli, M., Fanti, M. P. and Meloni, C. (2003): "Real time optimization of traffic signal control: application to coordinated intersections", In Proc. IEEE Int. Conf. on Systems, Man and Cybernetics, Washington, pp. 3288-3295.

Gabard, J. F. (1991): "Car following models", In Concise encyclopaedia of traffic and transportation systems, pp. 65-68, M. Papageorgiou (Ed.), Oxford: Pergamon Press.

Ganiyu, R. A., Olabiyisi, S. O., Omidiora, E. O., Okediran, O. O. and Alo, O. O. (2011): "Modelling and Simulation of a Multi-Phase Traffic Light Controlled T-type Junction Using Timed Coloured Petri Nets", American Journal of Scientific and Industrial Research, Vol. 2, No. 3, pp. 428-437.

Ganiyu, R. A., Omidiora, E. O., Olabiyisi, S. O., Arulogun, O. T. and Okediran, O. O. (2011a): "The underlying concepts of Coloured Petri Net (CPN) and Timed Coloured Petri Net (TCPN) models through illustrative example", Accepted Manuscript for Publication in International Journal of Physical Science, Paper No: ASCN/2011/012, African University Journal Series, Accra, Ghana
Huang, Y. S. and Chung, T. H. (2008): "Modeling and Analysis of Urban Traffic Lights Control Systems Using Timed CP-nets", Journal of Information Science and Engineering, Vol. 24, pp. 875-890.

Jensen, K. (1994): "An Introduction to the Theoretical Aspects of Coloured Petri Nets", A Decade of Concurrency, Lecture Notes in Computer Science, Springer-Verlag, Vol. 803, pp. 230-272.

Jensen, K., Kristensen, L. M. and Wells, L. (2007): "Coloured Petri Nets and CPN Tools for modelling and validation of concurrent systems", International Journal on Software Tools for Technology Transfer, Vol. 9, No. 3-4, pp. 213-254.

Murata, T. (1989): "Petri Nets: Properties, Analysis and Applications", Proceedings of the IEEE, Vol. 77, No. 4, pp. 541-580.

Papageorgiou, M. (1999): "Automatic control methods in traffic and transportation", In Operations research and decision aid methodologies in traffic and transportation management, P. Toint, M. Labbe, K. Tanczos and G. Laporte (Eds.), Springer-Verlag, pp. 46-83.

Papageorgiou, M., Diakaki, C., Dinopoulou, V., Kotsialos, A. and Wang, Y. (2003): "Review of road traffic control strategies", Proceedings of the IEEE, Vol. 91, No. 12, pp. 2043-2067.

Patel, M. and Ranganathan, N. (2001): "IDUTC: An Intelligent Decision-Making System for Urban TrafficControl Applications", IEEE Trans. on Vehicular Technology, Vol. 50, pp. 816-829.

Peterson, J.L. (1981): "Petri Net Theory and the Modeling of Systems", Prentice Hall, Englewood Cliffs, New Jersey.

Wey, W. M. (2000): "Model formulation and solution algorithm of traffic signal control in an urban network", Computers, environment and urban systems, Vol. 24, pp. 355-377. 